Pak. j. sci. ind. res. Ser. A: phys. sci. 2017 60(3)162-168

\title{
The Role of Yarn Counts and Polyester/Cotton Blends in Comfort of Knitted Fabric
}

\author{
Muhammad Qamar Tusief ${ }^{a *}$, Nabeel Amin ${ }^{\mathrm{b}}$, Nasir Mahmood ${ }^{\mathrm{a}}$, Muhammad Babar Ramzan ${ }^{\mathrm{b}}$ and \\ Hafiz Rehan Saleem ${ }^{\mathrm{a}}$ \\ ${ }^{a}$ Department of Fibre and Textile Technology, University of Agriculture, Faisalabad, Pakistan \\ ${ }^{\mathrm{b}} \mathrm{School}$ of Textile and Design, University of Management and Technology Lahore, Pakistan
}

(received August 25, 2016; revised August 8, 2017; accepted August 30, 2017)

\begin{abstract}
There have been three major concerns regarding the clothing comfort, psychological, sensorial and thermo-physiological comfort. However, there is lack of work on thermo-physiological comfort of knitted fabric. Hence the present study is conducted to fulfill this gap by analyzing physiological comfort in sense of air permeability, absorbency, vertical wicking and drying time of plain knitted fabric. Clothing comfort is mainly affected by type of fibres, yarn properties, structure of fabric, finishing treatments, and clothing conditions. In this study the effect of various yarn counts and polyester/cotton blend ratios on the comfort of knitted fabric has been analyzed using Statistical Package for the Social Sciences (SPSS). It is depicted from the results that the selected variables put direct influences on the thermo-physiological comfort of the knitted fabric. The increasing share of polyester in the blend and the fine count for yarn put negative impact on the comfort of the knitted fabric.
\end{abstract}

Keywords: yarn count, polyester/cotton blends, air permeability, drying time, absorbency

\section{Introduction}

The textile industry is going towards new lines of technical side with the changing demands of value added clothing. Clothing is not being used for aesthetic values only but some other special features like comfort.

Comfort is the pleasant state of physiological, psychological and physical harmony between human being and surrounding environment. Human mind responds different levels of satisfaction with the ever changing environment. This perception discloses the effect of clothing between human body and its surrounding atmosphere. A number of fibre, yarn and fabric properties are strongly related to the comfort and taken into account in manufacturing of suitable apparel items. Hence the selection of suitable fibre blends, yarn parameters and fabric construction techniques are of significant importance as they have major effect on thermo-physiological comfort level of the fabric (Kothari, 2006). The basic element of thermal comfort is the feeling of warmth-coolness and damp-dryness. This depends upon the air permeability of the fabric and its ability to absorb and evaporate the sweat from human skin. Clothing being next to skin should be an effective transporter and barrier of heat to maintain the thermal balance with the environment (Jhanji et al., 2015a; Hes, 2011). Exchange of heat between human *Author for correspondence; E-mail: qamartosief@yahoo.com body and its surroundings depends on many factors related to human organism, atmospheric conditions and properties of the clothing (Banerjee et al., 2013; Kaplan and Okur, 2012). The goal of this study is to analyze the impact of yarn count and polyester/cotton $(\mathrm{P} / \mathrm{C})$ blend ratios on thermo-physiological comfort of the knitted fabric.

Fibre blending has been a common practice in the textile industry for a long time. It is done to achieve quality products that cannot be realized using one fibre type alone. Blends combine the positive attributes of each of its component, reduce the negative properties and economize the material cost (Gahlot, 2011). Thus several researchers have investigated the effect of blend ratios of different fibres on yarn properties and the resultant fabric (Qamar and Israr, 2012). Blending of cotton with polyester usually produces some extra ordinary good results in the fabric. Polyester helps the fabric to retain its shape and resist stains and wrinkles while cotton makes the fabric more absorbent and comfortable (Klein, 1998). The ratio of natural and synthetic fibres in the blend plays a vital role in comfort of the knitted fabric. The high ratio of cellulosic fibre in the blend increases the moisture regain of the fabric that results in higher diffusivity of the material. Water vapors from the humid air (close to the sweating human skin) are absorbed by the hygroscopic fabric and released to the 
dry air. This increases the flow of water vapors from skin to the atmosphere (Kandhavadivu et al., 2015) that improves the comfort of the fabric.

Because of unique properties and features that affect the comfort of the fabric, many natural and synthetic fibres have their application in the manufacturing of knitted fabric. Several studies have been conducted to highlight the influence of fibre types, yarn count, yarn blends and fabric structure on the comfort of knitted fabrics (Jhanji et al., 2015b; Liu and Su, 2015). However, a combined analysis of thermo-physiological comfort of plain knitted fabric for various counts and blend ratios of $\mathrm{P} / \mathrm{C}$ has not been studied yet.

Keeping in view the significance of various kinds of the fibres and yarn count in comfort properties of the fabric the present study is planned. Here the optimum ratio of polyester/cotton fibres in their blends and different yarn count levels were investigated in order to get more efficient comfort properties in the plain knitted fabric.

\section{Materials and Methods}

Polyester and cotton fibre blends with four different ratios $(0 / 100,10 / 90,35 / 65$ and 50/50) were used to make yarn of three different counts i.e. $12 \mathrm{~s}, 16 \mathrm{~s}$ and 20 s. Then these yarns were used to manufacture the samples of plain knitted fabric with same GSM $\left(\mathrm{g} / \mathrm{m}^{2}\right.$. The detail description of the material used and methods applied in this research study is given below.

Yarn preparation. Yarn counts of 12s, 16s and 20s for cotton and the composite i.e. polyester-cotton were prepared at the different blend ratios $(0 / 100,10 / 90$, $35 / 65$ and 50/50) and tested for their tensile properties adopting the procedure as recommended by ASTM (2008a). The yarn properties are given in the Table 1 .

Knitting process. Circular knitting machine was engaged to make plain knitted fabric samples of constant weight per unit length (GSM) from P/C blended yarn of various counts as given in Table 1 . The specifications of the knitting machine used in this research are given below.

$\begin{array}{ll}\text { Brand } & =\text { Lonati } \\ \text { Width } & =14 " \\ \text { Stitch length } & =0.30 \\ \text { No. of needles } & =144 \\ \text { Voltage } & =380 \mathrm{~V} \\ \text { Machine speed } & =22 \mathrm{rpm}\end{array}$

Testing of knitted fabric characteristics. The knitted fabric samples made from ring spun yarn were placed on flat surface for $24 \mathrm{~h}$ at $65 \pm 2 \%$ relative humidity and $27 \pm 2 \%$ temperature for conditioning purpose. Then the following comfort related characteristics of the knitted fabric samples were observed and evaluated adopting standard test methods recommended for each test.

Air permeability. Air permeability is the rate of air flow that passes perpendicularly through unit area under a prescribed air pressure difference between the two surfaces of material. It is generally expressed as $\mathrm{cm}^{3} / \mathrm{cm}^{2} / \mathrm{sec}$. This is an important comfort related property of the fabric and was measured by adopting the procedure as described by ASTM (2008b) testing method. In this method the fabric sample is clamped into the tester and by using vacuum, the air pressure is made different on one side of the fabric. Due to this air flow takes place from one side of the fabric with higher pressure to the side with lower pressure. From this air flow rate, the air permeability of the fabric is determined.

Absorbency. Absorbency is the ability of the fabric to absorb and retain the moisture within its structure. It is the flow of the moisture through the fabric that significantly affects its comfort properties. Absorbency affects the moisture management ability of the fabric. This ability stops perspiration from remaining next to human skin and ultimately enhances the comfort ability of the fabric. All fabric samples, made according to the selected variables, were tested for their absorbency

Table 1. Yarn tensile properties for various yarn counts and $\mathrm{P} / \mathrm{C}$ blend ratios

\begin{tabular}{|c|c|c|c|c|c|c|c|c|c|c|c|c|}
\hline \multirow{2}{*}{$\begin{array}{l}\text { Yarn count } \\
\mathrm{P} / \mathrm{C} \text { blend ratios }\end{array}$} & \multicolumn{4}{|c|}{$\mathrm{C} 1=12 \mathrm{~s}$} & \multicolumn{4}{|c|}{$\mathrm{C} 2=16 \mathrm{~s}$} & \multicolumn{4}{|c|}{$\mathrm{C} 3=20 \mathrm{~s}$} \\
\hline & B0 & B1 & B2 & B3 & B0 & B1 & B2 & B3 & $\mathrm{B} 0$ & B1 & B2 & B3 \\
\hline & $0 / 100$ & $10 / 90$ & $35 / 65$ & $50 / 50$ & $0 / 100$ & $10 / 90$ & $35 / 65$ & $50 / 50$ & $0 / 100$ & $10 / 90$ & $35 / 65$ & $50 / 50$ \\
\hline Yarn CLSP & 2301 & 2510 & 3159 & 3457 & 2185 & 2485 & 2980 & 3853 & 2139 & 2746 & 3058 & 3480 \\
\hline Single yarn & & & & & & & & & & & & \\
\hline Strength (lbs) & 669 & 791 & 956 & 1020 & 480 & 539 & 636 & 851 & 369 & 480 & 534 & 635 \\
\hline Elongation (\%) & 4.32 & 4.66 & 5.55 & 6.77 & 5.78 & 5.93 & 7.77 & 8.67 & 6.14 & 6.83 & 8.7 & 9.22 \\
\hline
\end{tabular}


property by adopting the procedure as recommended by AATCC (2010) test method. In this method a drop of water is allowed to fall from a fixed height onto the taut surface of a test specimen. The time required for the specular reflection of the water drop to disappear is measured and recorded as wetting time.

Vertical wicking. Vertical wicking is another important comfort related property of the fabric. This is the ability of vertically aligned fabric specimens to transport liquid along and /or through them. It was calculated by adopting the test procedure as recommended by AATCC (2012a; 2012b). According to this method, test specimens as per recommendations are prepared. These specimens are clamped at their unmarked ends to hang them vertically over a beaker. Then the beaker is filled with $100 \mathrm{~mL}$ distilled water and the specimens are lowered down into the beaker to the 0.5 mark and timing is started. The samples are removed after $10 \mathrm{~min}$ and the water travel length through the specimens is noted that indicates its wick ability per unit time.

Drying time. The ability of the fabric to dry up also effects on its comfort. Hence the drying time of the fabric samples made in this research according to the selected variables was tested adopting the test procedure as per recommended by AATCC (2012a) standard test method. To determine the drying time of the fabric, the dry weight of the sample is first recorded then this sample is saturated with water according to its moisture regain level. After this the sample is placed in the dish resting on a weighing scale. A set air flow is created over the specimen and timing is started. When the fabric returns to its original weight, the time is recorded that is its drying time.

Analysis of data. Factorial experiment in completely randomized design (CRD) was applied in the analysis of data for testing the differences among various quality characteristics of knitted fabric. CRD is the simplest design for comparative experiments of homogeneous experimental units. It uses the basic principles of

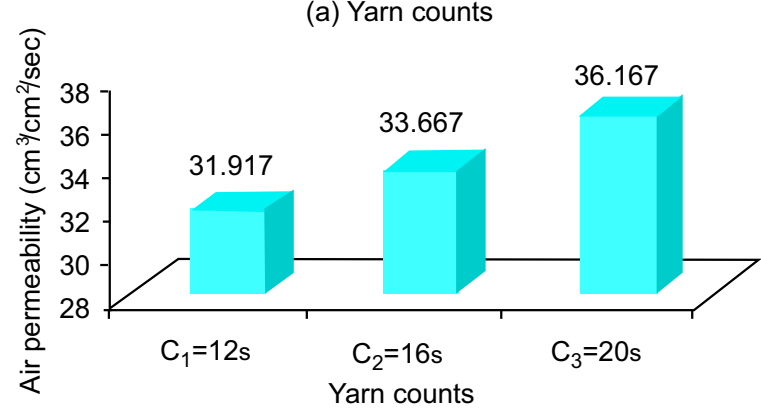

(b) P/C blend ratios

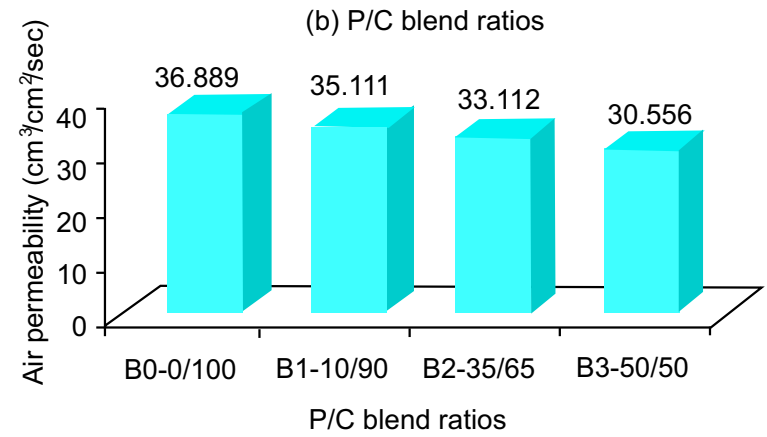

Fig. 1. Air permeability of knitted fabric for various (a) yarn counts and (b) P/C blend ratios absorbency

experimental design i.e. randomization and replication. In CRDs, the treatments are assigned to the experimental units in a completely random manner. It is a very flexible design by which statistical analysis is very simple as compared to other designs. In CRD the loss of information due to missing data is small as compared to other designs because there exist large number of degrees of freedom for the error source of variation. Duncan multiple range (DMR) test was used to make comparison of mean values.

\section{Results and Discussion}

The brief analysis of obtained results for each characteristic against the selected variables is described here.

Table 2. Comparison of mean values of fabric comfort properties for various yarn counts and $\mathrm{P} / \mathrm{C}$ blend ratios

\begin{tabular}{llllllll}
\hline \hline Knitted fabric comfort properties & \multicolumn{3}{c}{ Yarn counts } & \multicolumn{5}{c}{ Polyester/cotton blend ratios } \\
\hline & $\mathrm{C} 1=12 \mathrm{~s}$ & $\mathrm{C} 2=16 \mathrm{~s}$ & $\mathrm{C} 3=20 \mathrm{~s}$ & $\mathrm{~B} 0=0 / 100$ & $\mathrm{~B} 1=10 / 90$ & $\mathrm{~B} 2=35 / 65$ & $\mathrm{~B} 3=50 / 50$ \\
Air permeability $\left(\mathrm{cm}^{3} / \mathrm{cm}^{2} / \mathrm{sec}\right)$ & $31.917 \mathrm{c}$ & $33.667 \mathrm{~b}$ & $36.167 \mathrm{a}$ & $36.889 \mathrm{a}$ & $35.111 \mathrm{~b}$ & $33.112 \mathrm{c}$ & $30.556 \mathrm{~d}$ \\
Absorbency (sec) & $12.333 \mathrm{c}$ & $14.417 \mathrm{~b}$ & $15.417 \mathrm{a}$ & $6.667 \mathrm{~d}$ & $12.333 \mathrm{c}$ & $15.111 \mathrm{~b}$ & $22.111 \mathrm{a}$ \\
Vertical wicking (min) & $17.417 \mathrm{a}$ & $19.833 \mathrm{~b}$ & $21.500 \mathrm{c}$ & $23.667 \mathrm{a}$ & $21.000 \mathrm{~b}$ & $17.889 \mathrm{c}$ & $15.778 \mathrm{~d}$ \\
Drying time (min) & $20.333 \mathrm{a}$ & $18.250 \mathrm{~b}$ & $16.167 \mathrm{c}$ & $22.333 \mathrm{a}$ & $19.778 \mathrm{~b}$ & $16.778 \mathrm{c}$ & $14.333 \mathrm{~d}$ \\
\hline \hline
\end{tabular}

Any two values not sharing a letter in common differ significantly at 0.05 level of probability. 
Air permeability. The comparison of individual treatment means of air permeability for yarn counts $\left(\mathrm{C}_{1}\right.$, $\mathrm{C}_{2}$, and $\mathrm{C}_{3}$ ) is presented in Table 2. These results are also highlighted in Fig. 1. It is clear from the findings that as the value of yarn count changes from $12 \mathrm{~s}$ to $16 \mathrm{~s}$, significant change in the value of air permeability is also observed from 31.917 to $36.167\left(\mathrm{~cm}^{3} / \mathrm{cm}^{2} / \mathrm{sec}\right)$. The results reveal that 20 s yarn count gives the maximum value while the minimum value is recorded for $12 \mathrm{~s}$ yarn count. These observations are well supported from the research study that the air permeability had a direct relationship with the count of the yarn and was a function of knitted fabric thickness, tightness factor and porosity (Ajmeri and Bhattcharya, 2013). For the same fabric weight $\left(\mathrm{g} / \mathrm{m}^{2}\right)$, the finer yarn give better fabric cover than the coarser yarn due to higher number of yarn per unit area of fabric, which directly affects the air permeability of the fabric (Das et al., 2009). The increase in the thickness of yarn caused a decrease in air permeability (Kotb, 2012).

The mean values of fabric air permeability against various $\mathrm{P} / \mathrm{C}$ blend ratios as given in Table 2 and signified by Fig. 1 reflect that with the increase of the ratio of polyester in blend, air permeability of the knitted fabric decreased. These results are in line with the previous findings that the air and water permeability of the fabric decreased with increased in polyester proportion (Das et.al, 2009).

The values of absorbency time of the fabric for various yarn counts are given in Table 2 . These values differ significantly from one another. The results are also explained in Fig. 2. It is clear from these observations that 20s yarn count gave the maximum value while the minimum value was recorded for $12 \mathrm{~s}$ yarn count. This indicates that with the increase of yarn count the fabric absorbency time increases. It is because as the yarn count becomes fine the capillary action becomes slow due to less number of spaces among the fibres in the yarn. These findings get support from the results of a previous study that cotton is widely used in fabrics, especially in those applications where moisture absorption is highly desirable, as in underwear and towels. In this respect, not only the total amount of liquid that can be absorbed is important, but also the speed of the absorption process capillary action is also important (Meeren et al., 2002).

The data regarding the fabric absorbency for various $\mathrm{P} / \mathrm{C}$ blends as presented in Table 2 and illustrated by
Fig. 2 reveals that blend ratio $(50 / 50)$ gave the maximum absorbency time while the minimum absorbency time was recorded for blend ratio $(0 / 100)$ depicts that with the increase of polyester ratio in the blend the absorbency capability of the material decreases. These results are in line with the findings that absorbency of $100 \%$ cotton was excellent as compared to $100 \%$ polyester. Absorbency rate of polyester is low and exhibits extremely poor water penetration while cotton showed excellent water absorbency. The water absorbency of a blend is indirectly proportional to its polyester content that means as the polyester content increases, the water absorbency decreases (Kalsoom, 1996).

The results of vertical wicking time of the knitted fabric for different yarn counts $\mathrm{C}_{1}, \mathrm{C}_{2}, \mathrm{C}_{3}$ are shown in Table 2 and graphically represented in Fig. 3. These values disclose that 20 s yarn count gave the maximum wicking time while the minimum wicking time was recorded for $12 \mathrm{~s}$ yarn count. This means finer count decreases the wick ability of the knitted fabric. These results are in line with the findings of a previous study that the fabric sample produced with coarser yarn count shows highest capillary height as compared to that with finer yarn count that influence its wicking property (Babu and Koushik, 2011). Similarly, in another work

(a) Yarn counts

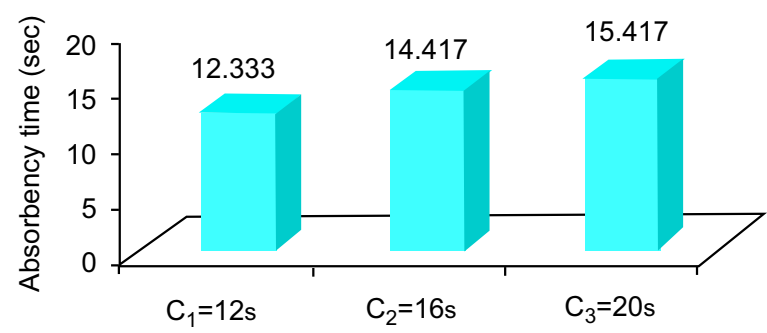

(b) P/C blend ratios

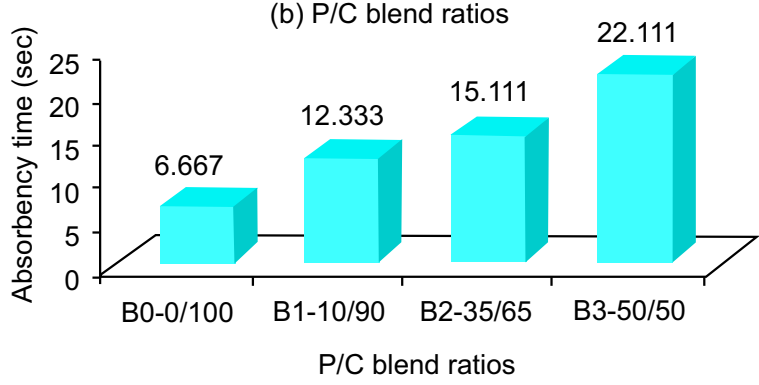

Fig. 2. Absorbency of knitted fabric for various (a) yarn counts and (b) $\mathrm{P} / \mathrm{C}$ blend ratios vertical wicking 
(a) Yarn counts

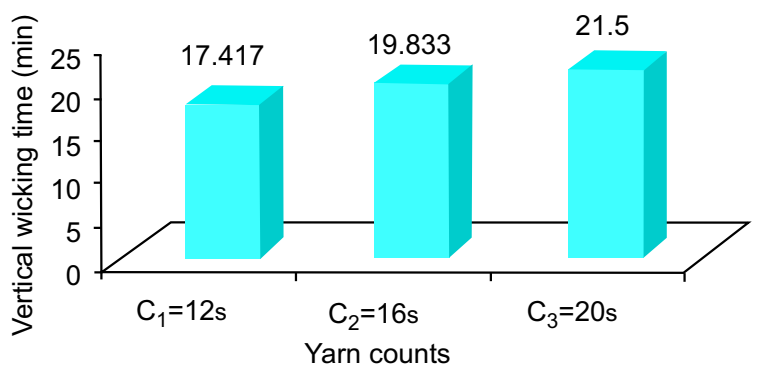

(b) $\mathrm{P} / \mathrm{C}$ blend ratios

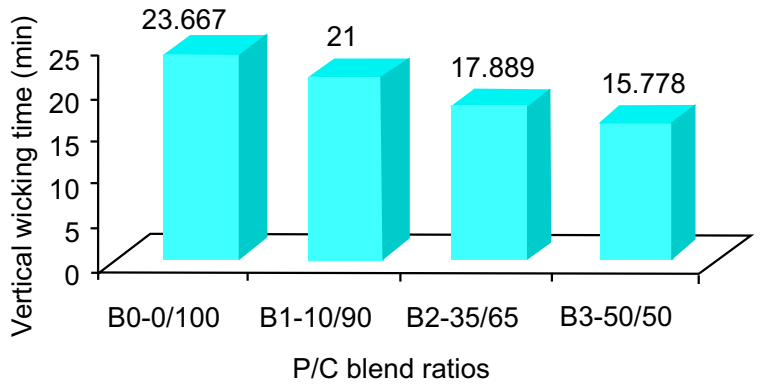

Fig. 3. Vertical wicking of knitted fabric for various (a) yarn counts and (b) P/C blend ratios

it was found that the yarn count had great impact on wicking performance of knitted fabrics and wicking ability of fabric increased with the use of coarse yarns (Das et al., 2009; Ozturk et al., 2011).

The mean values of vertical wicking for various $\mathrm{P} / \mathrm{C}$ blends $\mathrm{B} 0, \mathrm{~B}_{1}, \mathrm{~B}_{2}$ and $\mathrm{B}_{3}$ are given in Table 2 and signified by Fig. 3 . The results very clearly reflect a decreasing trend in vertical wicking time of the knitted fabric with the increase of polyester ratio in the blend. These findings correlate with the results of a former study that the better wicking ability of fabric made from synthetic yarns might be due to lower moisture absorption capability of the polyester fibre which does not allow water to enter inside. As a result, water movement and absorption occur only on the fibres surface. However, moisture absorption of cotton fibre is higher. Water diffuses into the cotton fibre and cotton starts to swell immediately after water absorption. This might be the reason for the lower wicking ability of the cotton yarns. In addition, differences in yarn surface roughness causes differences in wicking of yarns and fabrics made from those yarns. Increase in yarn roughness due to random arrangement of its fibres gives rise to a decrease in the rate of water transport. Due to increase of the yarn roughness, the effective advancing contact angle of water on the yarn is increased. With this random fibre arrangement the continuity of capillaries formed by the fibres of the yarn seems to be decreased. Cotton fibres might have formed rough yarns of high apparent contact angle due to their convolutions and might be more randomly distributed whereas synthetic fibres might have smoother surface which would affect the contact angle (Ozturk et al., 2011).

The comparison of individual mean values of drying time of the knitted fabric for various yarn counts $C_{1}$, $\mathrm{C}_{2}, \mathrm{C}_{3}$ as presented in Table 2 and shown in Fig. 4 clears the fact that as the count of yarn becomes fine the drying time of the fabric decreases. These results are well supported from the research study in which it was observed that as the yarn count increased the drying time of the fabric decreased (Crow and Osczeyski, 1993).

The mean values of drying time for different $\mathrm{P} / \mathrm{C}$ blend ratios are given in Table 2 and highlighted in Fig. 4. The results depict that as the ratio of the polyester in the blend increased the drying time of the fabric decreased. These findings are also in line with the observations made in previous study that improvement in drying time is achieved in the case of the polyestercotton stripe samples. Further, indications of internal

(a) Yarn counts

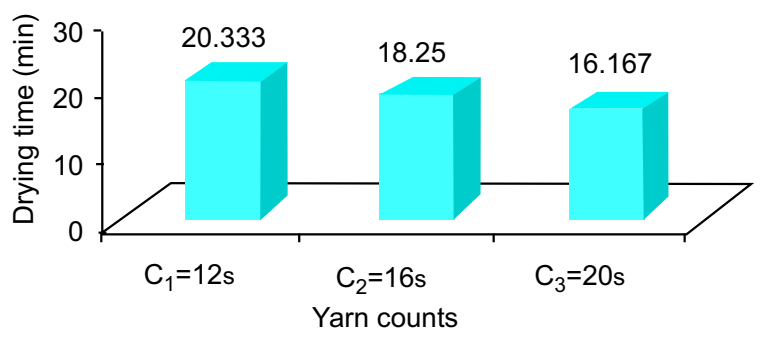

(b) P/C blend ratios

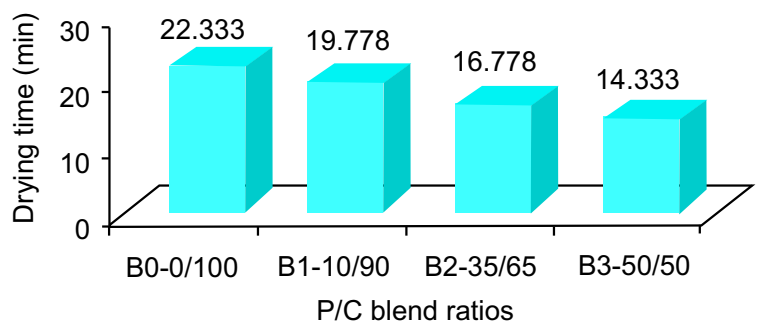

Fig. 4. Drying time of knitted fabric for various (a) Yarn counts and (b) P/C blend ratios 
water movement from polyester to cotton portion have been obtained by tracking the surface temperatures of the knit hoses during drying (Gurudatt et al., 2010).

\section{Conclusion}

The present research study was planned to investigate the effect of yarn counts and polyester/cotton blend ratios on the comfort related properties of the knitted fabric in order to pave a guide path for the manufacturers and users to make a right choice for their products.

The effect of polyester/cotton $(\mathrm{P} / \mathrm{C})$ fibre blend ratios, yarn count on physiological and moisture management related comfort properties of plain knitted fabric were observed. The yarn samples of three different counts were prepared with four variant $\mathrm{P} / \mathrm{C}$ blends. Then these yarns were used to make plain knit fabric of same GSM. The resultant fabric was analyzed for its comfort properties like air permeability, absorbency, vertical wicking and drying time using SPSS software. A direct influence of the selected variables was found on these properties with the following conclusions.

- Yarn count and polyester/cotton blend ratios have significant effects on the comfort properties of the fabric.

- Fabric air permeability, absorbency and vertical wicking time increased as the count of yarn became fine, while drying time decreased with fine count.

- As the share of the polyester fibre in the blend increased, fabric air permeability, vertical wicking time and drying time decreased, while absorbency time increased.

From the above findings it is depicted that finer count and increased share of polyester in the blend put negative impact on the comfort related properties of the $\mathrm{P} / \mathrm{C}$ plain knitted fabric.

\section{References}

AATCC, 2012a. Moisture Management Measurement of Fabric. American Association of Textile Chemists and Colorists, U.S.A.

AATCC, 2012b Test Method for Vertical Wicking. American Association of Textile Chemists and Colorists, U.S.A.

AATCC, 2010. Test Method for Absorbency of Textile. American Association of Textile Chemists and Colorists, U.S.A.

Ajmeri, J.R., Bhattcharya, S.S. 2013. Comparative analysis of thermal comfort properties of knitted fabrics made of cotton and modal fibres. International Journal of Textile \& Fashion Technology, 3: 1-10.

ASTM, 2008a. Standard Test Methods for Measurement of Fabric Properties. American Society for Testing and Materials, Philadelphia, U.S.A.

ASTM, 2008b. Standard Test Method for Measurement of Yarn porperties. American Society for Testing and Material, Philadelphia, U.S.A.

Babu, R. V., Koushik, C.V. 2011. Capillary rise in woven fabrics by electrical principle. Indian Journal of Fibre \& Textile Research, 36: 99-102.

Banerjee, D., Chattopadhyay, S.K., Yuli, S. 2013. Infrared thermography in material research- A review of textile applications. Indian Journal of Fibre \& Textile Research, 38: 427-437.

Crow, M.R., Osczeyski, R. J. 1993. The Effect of Fibre and Fabric Properties on Fabric Drying Time. Defence Research Establishment, Ottawa, Canada.

Das, B., Das, A., Kothari, V., Fangueiro, R., Araujo, M.D. 2009. Moisture flow through blended fabricseffect of hydrophilicity. Journal of Engineering Fibre \& Fabric, 4: 20-28.

Gahlot, M. 2011. Properties of oak tasar/viscose blended yarns. Indian Journal of Fibre \& Textile Research, 36: 187-189.

Gurudatt, K., Nadkarni, V.M., Khilar, K.C. 2010. A study on drying of textile substrates and a new concept for the enhancement of drying rate. Journal of Textile Institute, 101: 635-644.

Hes, L. 2011. Effect of composition of knitted fabrics on their cooling effeciency at stimulated sweating. Indian Journal of Fibre \& Textile Research, 36: 281-284.

Jhanji, Y., Gupta, D., Kothari, V.K. 2015a. Liquid transfer properties and drying behaviour of plated knitted fabrics with varying fibre types. Indian Journal of Fibre \& Textile Research, 40: 162-169.

Jhanji, Y., Gupta, D., Khothari, V.K. 2015b. Comfort properties of plated knitted fabrics with varying fibre type. Indian Journal of Fibre \& Textile Research, 40: 11-18.

Kalsoom, M.S., 1996. Effect of Abrasion, Crease Recovery, Tensile Strength and Hydrophilic Properties of Contemporary Cotton/Synthetic Fibre Blends. Ph.D. Thesis, Punjab University Lahore Pakistan.

Kandhavadivu, P., Rathinamoorthy, R., Surjit, R. 2015. Moisture and thermal management properties of 
woven and knitted tri-layer fabrics. Indian Journal of Fibre \& Textile Research, 40: 243-249.

Kaplan, S., Okur, A. 2012. Thermal comfort performance of sports garments with objective and subjective measurements. Indian Journal of Fibre \& Textile Research, 37: 46-54.

Klein, W. 1998. The Technology of Short Staple Spinning, Manual of Textile Technology, pp. 18-21, The Textile Institute, Manchester, UK.

Kotb, A.N. 2012. The perception of plain woven fabric's performance using regression analysis. Journal of Basic Applied Scientific Research, 2: 20-26.

Kothari, V.K. 2008. Thermo-physiological comfort characteristics and blended yarn woven fabric. Indian Journal of Fibre \& Textile Research, 31: $177-186$
Liu, X., Su, X. 2015. Properties of knitted fabric made from modified ring spun yarn. Indian Journal of Fibre \& Textile Research, 40: 282-287.

Meeren, P.V.D., Flores, S., Demeyere, H., Dedeecq, M. 2002. Qunatifying wetting and wicking phenomenon in cotton terry as affected by fabric conditioner treatement. Textile Research Journal, 72: $423-428$

Ozturk, M.K., Nergis, B., Candan, C. 2011. A study of wicking properties of cotton-acrylic yarns and knitted fabrics. Textile Research Journal, 81: 324328.

Qamar, T.M., Israr, A. 2012. Spinning and knitting of Flax, Bamboo and Soybean Fibre Blends. pp.5-60, LAP LAMBERT Academic Publishing GmbH \& Co.KG Saarbrucken, Germany. 